
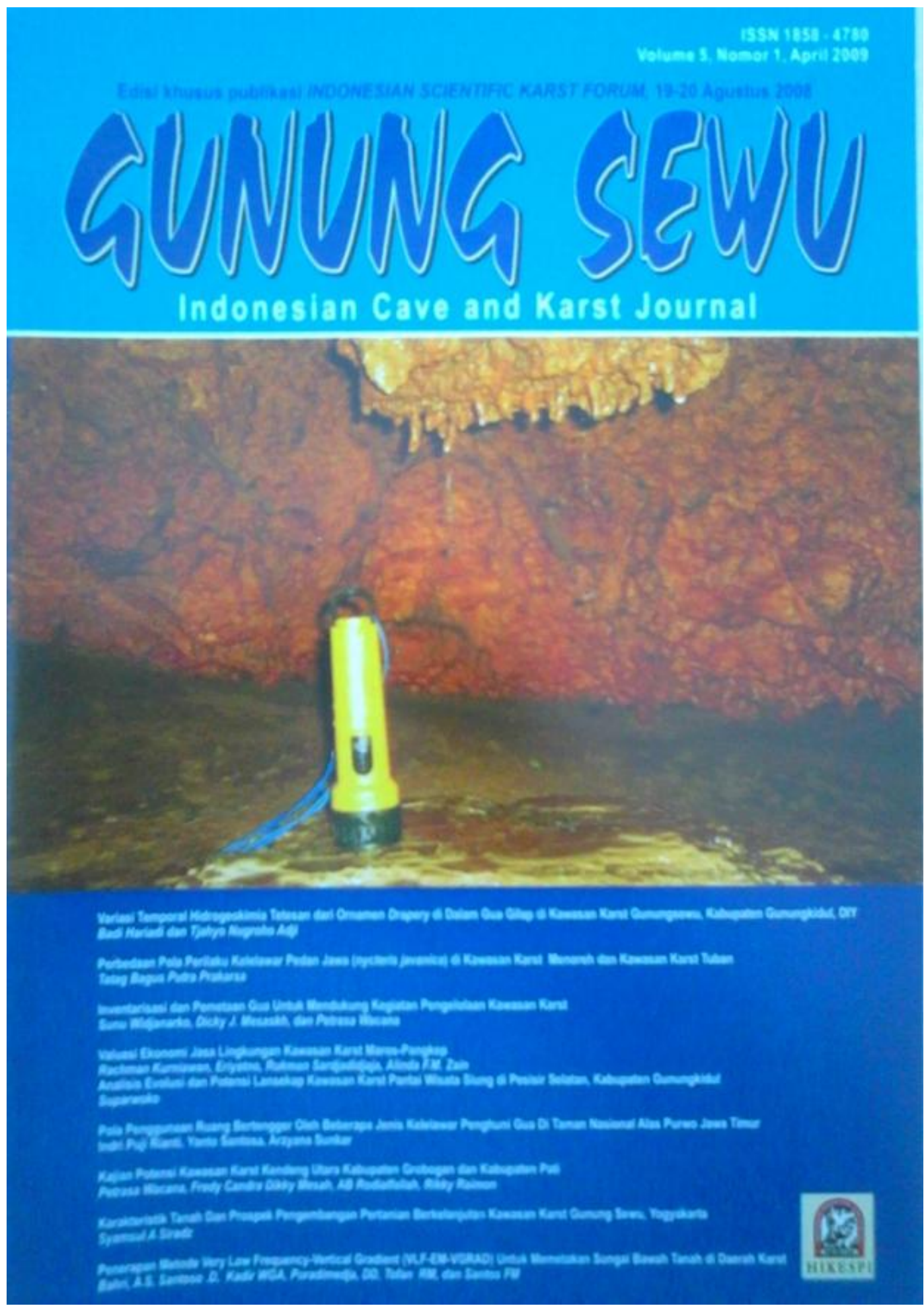

Create PDF with GO2PDF for free, if you wish to remove this line, click here to buy Virtual PDF Printer 


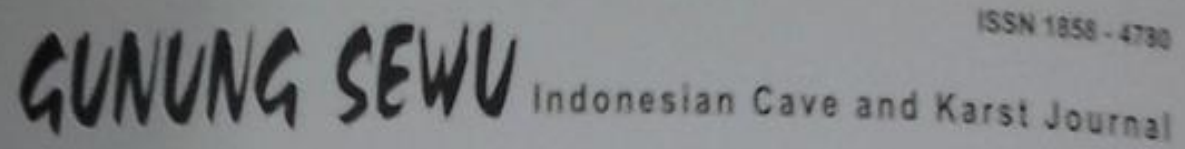

Terbit April dan November

Published online: www jurnalkarst.or id

Diterbitkan oleh: Himpunan Kegiatan Speleologi Indonesia (HIKESPI)

Seiunasama dengan Forum Karst Goenoeng Sewoe - Indonesian Caver Society - Subtem Combath

Pemimpin Umum

Cahyo Alkantana

Ketua HIKESPI

Telephone: +62.8123650725

e-mail: alkantana_cahyo@yahoo.com

\section{Editor}

Eko Haryono (Geomortologi Kanst)

Fabultas Geografi UGM Yogyakarta 5sza!

Telephone $+62-274 \cdot 902332$

Fax: $+62-274-589595$

e-makt e haryonoggeo ugm.acid

Cahyo Rahmadi (Blospeloologi Karst)

Bidang Zoologi Pusit Biologi LiPi Cibinong

Telephone, $+62-8159948333$

e-mat cahyo rahmadiglipigo id

J.Susetyo Edi Yuwono (Avkeologi Karst)

Fakullas limu Budaya UGM, Yogyakarta 55281

Telephone: $+62-81802618328$

Erral: selyoedi Byahoo com
Pemimpin Redaksi

Tjahyo Nugroho Adji

Fakultas Geografi UGM, Yogyakara sE:s:

Telephone: $+62-274-6492332$

Fax: $+62-274-569695$

e-mail: adi/Egeougmacid

Sulastana Raharja (Geologi Kast)

hoonesian Caver Society

(awa indocavertong)

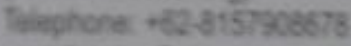

tonal: sha Gethevion com

Sunu Widjanarko (Pametasn Gaj)

Subtems Comnunity (www sublena arid)

Telephone +62-8156715299

emal sunu widjanaroggrnal con

Bagus Yulianto (Penelusuran dan Folyysi Bur

Acintyacunyata Spelediogical Cib

Telieghone +62-8122819753

Tjahyo Nugroho Adji (Hidiolog Kast

Fakitas Geograt UGu Yogajora 56s:

Telephone + $62.274-6492332$

Fax: $+62-274-689695$

email aclisgeo ugnacid 
GUNUNG SEWU

Volume 5, Nomor 1, April 2009

Variasi Temporal Hidrogeokimia Tetesan dari Omamen Drapery di Dalam Gua Glap di Kawasan Karst Gunungsewu, Kabupaten Gunungkidu, DrY Bad Hariadi dan Tjahyo Nugroho Adji

Perbedaan Pola Penilaku Kelelawar Pedan Jawa (nycteris javanica) de

Kawasan Karst Menoreh dan Kawasan Karst Tuban

Tatag Bagus Putra Prakarsa

Inventarisasi dan Pemetaan Gua Untuk Mendukung Kegialan Pengelolaan

Kawasan Karst

Sunu Widjanarko, Dicky J. Mesaskh, dan Petrasa Wbcana

Valuasi Ekonomi Jasa Lingkungan Kawasan Karst Maros fangkep

Rachman Kumiawan, Enyyatno, Rukman Sardfadidjà. Alnde FU. Zain

Analisis Evolusi dan Potensi tarsekap Kawasan Karst Partai Wisata

Siung di Pesisir Selatan, Kabupaten Gunungkidul

Suparwoko

Pola Penggunaan Ruang Bertengger Oleh Beberapa Jenis Keilelawar

Penghuni Gua Di Taman Nasionai Alas Purwo Jawa Timur

Indri Pull Riant, Yunto Santosa, Arzyana Sunkar

Kajan Potensi Kawasan Karst Kendeng Utara Kabupaten Grobogan dan

Katupaten Pat

Antrasa Wacana, Frody Candra Dikky Mesah, AB Rodiallallah, Rikky

Ramon

Karakteristk Tanah Dan Prospek Pengembangan Pertanian Berkelanjutan

Kawasan Karst Gunung Sewu, Yogyakarta

14

21

Syamsil A Siradz

Punerapan Metode Very Low Frequency-Vertical Gradient MLF-EM.

VGRAD) Untuk Memetakan Sungai Bawah Tanah di Daerah Karst

Banti A.S, Santoso D. Kadir WGA, Puradimedja, DD, Totan RM, dan 


\title{
Variasi Temporal Hidrogeokimia Tetesan dari Ornamen Drapery di Dalam Gua Gilap dii Kawasan Karst Gunungsewu, Kabupaten Gunungkidul, DIY
}

Badi Hariadi dan Tjahyo Nugroho Adji

\begin{abstract}
The hydrogeochemical research of droplets from drapery conducted from May 2006 until March 2007 is took place within the Gilap Cave as the headwaters of Bribin underground river. The purpose of this study is to determine the effect of the intensity drop of the season, the relationship between the intensity drops with the major chemical composition of droplets and the relationship between the intensity drops with the aggressiveness of the drops. The rainfall data was obtained through a mini rain observation stations installed in several places around the research area. The content of major chemical constituents of water droplets is obtained through laboratory analysis of samples originating from droplets of water that is taken once a month, which is then carried out analysis of the saturation index with respect to calcite mineral aided by Aquachem 4.0 software. Cave drapery ornament in lustrous ornaments chosen is within easy reach. The analysis conducted is a descriptive analysis by making a graph of correlation between variables. The results show that the intensity of water droplets originating from the ornament with the flow system fissure tends to be high during the wet season, the value of TDS, EC, Eh, the content of $\mathrm{Ca}^{2}$ ?:the content of HCO3?'and PCO2'measured too high, while the pH tends to sour and SI calcite tend to be undersaturated. In contrast, during the dry season, relatively low intensity drops, the value of TDS, EC, Eh, the content of $\mathrm{Ca}^{2}$ ?FHCO3\# content, and also measured PCO 2tiow, whereas alkaline pH and SI calcite tends to be supersaturated. At the time of the aggressiveness of supersaturated droplets, droplets tend to alkaline pH, PCO2, $\mathbb{C} \mathrm{C}$, and Eh drops low, while HCO3? content, content of $\mathrm{Ca}^{2}$ ?cand high-value drops TDS. Conversely, when the aggressiveness undersaturated droplets, droplets tend to be acidic of pH, $\mathrm{PCO}$ 2, DHL, and high drop of Eh, while HCO3? content, $\mathrm{Ca}^{2}$ ?content, and the low value of TDS occurs. The conclusion is that the droplets hidrogeokimia conditions influenced by seasonal conditions or controlled by terinfiltrasi rainfall into the ground. At the time of high rainfall, groundwater flow system into the fissure to be more aggressive to dissolve the mineral calcite, whereas during low rainfall, groundwater became less aggressive because it is saturated to the mineral calcite.
\end{abstract}

Keywords: karst aggressiveness, fissure flow, hidrogeokimia, drip

\section{Intisari}

Penelitian hidrogeokimia tetesan ornamen drapery yang dilakukan dari bulan Mei 2006 hingga bulan Maret 2007 ini mengambil lokasi di Gua Gilap sebagai daerah hulu dari sungai bawah tanah Bribin. Tujuan dari penelitian ini adalah untuk mengetahui pengaruh musim terhadap intensitas tetesan, hubungan antara intensitas tetesan dengan komposisi kimia mayor tetesan dan hubungan antara intensitas tetesan dengan agresivitas tetesan. Data curah hujan diperoleh melalui pengamatan pada stasiun hujan mini yang dipasang di beberapa tempat di sekitar daerah lokasi penelitian. Kandungan unsur kimia mayor air tetesan diperoleh melalui analisis laboratorium yang berasal dari sampel air tetesan yang diambil sekali tiap bulannya, yang kemudian dilakukan analisis indeks kejenuhannya terhadap mineral kalsit dengan software Aquachem 4.0. Ornamen drapery di dalam Gua Gilap yang dipilih merupakan ornamen yang mudah dijangkau. Analisis yang dilakukan adalah analisis deskriptif dengan cara membuat grafik korelasi antar variabel. Hasil penelitian menunjukkan bahwa intensitas air tetesan yang berasal dari ornamen dengan sistem aliran fissure cenderung tinggi saat bulan-bulan basah, nilai TDS, DHL, Eh, kandungan $\mathrm{Ca}^{2}$ ? $\tilde{N}$ kandungan HCO3?; dan PCO2; terukur juga tinggi, sedangkan pH cenderung asam dan SI kalsit cenderung undersaturated. Sebaliknya, saat bulan-bulan kering, intensitas tetesan relatif rendah, nilai TDS, DHL, Eh, kandungan $\mathrm{Ca}^{2}$ ?, kandungan $\mathrm{HCO}$ ?, dan $\mathrm{pCO} 2$ terukur juga rendah, sedangkan $\mathrm{pH}$ cenderung basa dan SI kalsit cenderung supersaturated. Pada saat agresivitas tetesan supersaturated, $\mathrm{pH}$ tetesan cenderung basa; pCO2,zDHL, dan Eh tetesan rendah; sedangkan kandungan HCO3ä̈kandungan $\mathrm{Ca}^{2}$ ?ädan nilai TDS tetesan tinggi. Sebaliknya, pada saat agresivitas tetesan undersaturated, $\mathrm{pH}$ tetesan cenderung asam; PCO2,NDHL, dan Eh tetesan tinggi; sedangkan kandungan HCO3AN kandungan $\mathrm{Ca}^{2}$ ?, dan nilai TDS tetesan rendah. Kesimpulan yang diperoleh adalah bahwa kondisi hidrogeokimia tetesan dipengaruhi oleh kondisi musim atau dikontrol oleh curah hujan yang terinfiltrasi ke dalam tanah. Pada saat curah hujan tinggi, airtanah yang memasuki sistem aliran fissure menjadi lebih agresif untuk melarutkan mineral kalsit, sedangkan pada saat curah hujannya rendah, airtanah menjadi tidak agresif karena sudah jenuh terhadap mineral kalsit.

Kata kunci : agresivitas karst, aliran fissure, hidrogeokimia, tetesan

Badi Hariadi ; Tjahyo Nugroho Adji

Kelompok Studi Karst, Fakultas Geografi

UGM, Yogyakarta, 55281

Telp : 62-8122967492

Email : adji@geo.ugm.ac.id

bedi_email05@yahoo.com

\section{Pendahuluan}

Tetesan pada atap gua merupakan

hasil perkolasi air hujan yang terjadi di 
permukaan tanah yang mengalir melalui pori-pori (diffuse) maupun percelahretakan (fissure) pada batuan karbonat. Air yang menetes tersebut, sebelumnya telah melarutkan batuan karbonat di atasnya karena banyak mengandung $\mathrm{CO}_{2}$ yang diperolehnya dari tanah maupun dari atmosfer dan dalam kondisi jenuh dapat membentuk ornamen-ornamen gua. Dekomposisi mineral kalsit di dalam larutan tersebut hanya dapat terjadi pada kondisi tertentu, salah satunya adalah pada saat tingginya tingkat penguapan akibat kelembaban udara yang rendah, serta kondisi agresivitas airtanah. Hal ini dapat terjadi pada daerah dengan kondisi iklim yang kering seperti di Indonesia dengan iklim tropis dan memiliki curah hujan yang tinggi. Selain itu, air tetesan merupakan sumber dari baseflow atau aliran dasar di waktu musim kemarau pada sungai bawah tanah di daerah karst (Hariadi, 2008).

Agresivitas airtanah merupakan sifat yang menunjukkan mudah atau tidaknya air untuk melarutkan mineral batuan. Klasifikasi agresivitas tersebut menggunakan klasifikasi berdasarkan indeks kejenuhan atau Saturation Indices (SI). Klasifikasi tersebut dapat digunakan untuk mengetahui proses hidrogeokimia yang terjadi pada mineral kalsit $\left(\mathrm{CaCO}_{3}\right)$ mengenai kemampuan airtanah untuk melarutkan mineral kalsit. Proses hidrogeokimia yang terjadi adalah kondisi airtanah yang masih mampu untuk melarutkan kalsit, ataukah kondisi airtanah dalam keadaan setimbang (equilibrium), ataukah kondisi airtanah dalam kondisi jenuh terhadap mineral kalsit sehingga memungkinkan untuk terbentuknya padatan berupa ornamen.

Suhartono \& Subanar (2005), menyatakan bahwa analisis secara temporal merupakan analisis yang dilakukan untuk mengidentifikasikan fenomena alami yang terbentuk sebagai akibat rangkaian pengamatan dan juga untuk memprediksikan kejadian atau fenomena yang akan terjadi di masa yang akan datang. Analisis secara temporal didasarkan pada anggapan bahwa urutan nilai-nilai yang diperoleh merupakan hasil dari pengukuran yang dilakukan secara temporal. Studi variasi temporal yang dilakukan adalah untuk memperoleh gambaran mengenai variasi kandungan hidrokimia selama waktu pengamatan (White, 1988).

Indonesia memiliki dua macam musim berdasarkan kondisi curah hujan, yaitu musim hujan dan musim kemarau. Pada waktu musim hujan, simpanan airtanah pada kawasan karst akan semakin banyak, dan sebaliknya, apabila lama tidak terjadi hujan (musim 
kemarau), maka simpanan airtanah akan semakin berkurang. Variasi kondisi musim mengakibatkan terjadinya variasi hidrogeokimia airtanah yang terjadi pada daerah karst. Oleh karena itu, perlu dilakukan penelitian mengenai variasi hidrogeokimia airtanah pada daerah karst untuk mengetahui perbedaan kondisi hidrogeokimia airtanah pada daerah karst tersebut pada saat musim kemarau dan musim hujan.

Dari penjelasan di atas, maka dapat dirumuskan pertanyaan: (1)apakah ada keterkaitan antara musim (curah hujan) dengan variasi intensitas tetesan pada ornamen drapery di dalam Gua Gilap? (2)apakah ada keterkaitan antara intensitas tetesan dengan variasi komposisi kimia mayor air tetesan pada ornamen drapery di dalam Gua Gilap? (3) bagaimana hubungan antara intensitas tetesan dengan agresivitas tetesan pada ornamen drapery di dalam Gua Gilap?

\section{Kondisi Gua Gilap dan sekitarnya}

Gua Gilap terletak di Dusun Klumpit, Desa Kenteng, Kecamatan Ponjong, Kabupaten Gunungkidul, Daerah Istimewa Yogyakarta (DIY). Geomorfologi daerah penelitian secara umum mempunyai bentuklahan asal proses solusional, pada satuan geomorfologi perbukitan kerucut karst
Gunungsewu. Kawasan karst Gunungsewu ini merupakan salah satu karst tropis dunia yang berkembang secara baik dan termasuk dalam tipe Holokarst. Holokarst merupakan tipe karst yang mempunyai bentanglahan lengkap yang terbentuk dari pelarutan batuan karbonat yang sangat mudah larut (Haryono dan Adji, 2005). Karst Gunungsewu membentang luas di bagian selatan Daerah Istimewa Yogyakarta, dari ujung barat yang berbatasan langsung dengan Kabupaten Bantul, Daerah Istimewa Yogyakarta, memanjang ke timur hingga Kabupaten Pacitan, Jawa Timur. Daerah penelitian terdapat pada Formasi Wonosari dengan batuan penyusun berupa batugamping terumbu. Batugamping penyusun batuan daerah penelitian adalah batugamping karstik yang memperlihatkan topografi kasar, karren, lapies, dan dicirikan oleh jaringan porositas sekunder berupa pembuluh, rongga, serta saluran-saluran hasil pelarutan. Batuan dasar yang menjadi alas sistem akuifer di daerah Gunungsewu merupakan batuan vulkanik tua. Sebagian batuan vulkanik tersebut bersifat keras dan pejal yang berasal dari lava dan breksi. Ketebalan maksimum batugamping pada Kawasan Karst Gunungsewu ini diperkirakan mencapai 650 meter. 


\section{Metode Penelitian}

Sampel tetesan yang berasal dari ornamen drapery di dalam Gua Gilap diambil sebanyak 7 kali selama satu tahun. Pengukuran intensitas tetesan, pH, Eh, temperatur, dan konduktivitas dilakukan secara langsung di lapangan. Sampel tetesan tersebut kemudian dianalisis di laboratorium untuk diketahui kandungan kimia mayor yang terkandung di dalamnya. Unsur kimia mayor yang dianalisis antara lain adalah $\mathrm{Ca}^{2+}, \mathrm{Mg}^{2+}, \mathrm{Na}^{+}, \mathrm{Cl}-\mathrm{HCO}_{3}{ }^{-}$, dan $\mathrm{SO}_{4}-$ Setelah diketahui besar kandungan unsur-unsur tersebut (dalam satuan epm), kemudian dilakukan analisis indeks kejenuhannya terhadap mineral kalsit (SI calcite)) menggunakan software Aquachem 4.0. Selain itu, dianalisis pula besar kandungan gas $\mathrm{CO}_{2}$ yang terlarut $\left(\log \mathrm{PCO}_{2}\right)$. Selanjutnya, dari besaran nilai hidrogeokimia tetesan yang diperoleh tersebut dilakukan analisis regresi linear menggunakan software Microsoft Office Excel 2007, antara musim (diwakili oleh kondisi curah hujan bulanan selama waktu penelitian) dengan kondisi hidrogeokimia tetesan tersebut untuk memperoleh gambaran mengenai variasi hidrogeokimia selama satu tahun pengamatan.

\section{Hasil dan Pembahasan}

Dari Tabel 1.1, tampak bahwa pengamatan dilakukan sebanyak 7 kali pada bulan Mei 2006, Juli 2006, Agustus 2006, September 2006, November 2006, Desember 2006, dan Maret 2007. Intensitas semakin berkurang seiring dengan berkurangnya curah hujan, dan akan meningkat searah dengan peningkatan curah hujan (Gambar 1.1). Hal tersebut menunjukkan bahwa curah hujan berpengaruh terhadap besaran intensitas tetesan. Respon peningkatan intensitas tetesan terjadi cukup cepat, yang kemungkinan disebabkan oleh sifat imbuhan akuifer yang terletak di atas Gua Gilap. Tipe pelorongan yang dominan adalah fissure yaitu berupa retakan dengan ukuran menengah. Kondisi tersebut terlihat pada batuan di sekitar permukaan di sekitar atap Gua

Tabel 1 Hidrogeokimia Tetesan dari Ornamen Drapery di Dalam Gua Gilap

\begin{tabular}{|c|c|c|c|c|c|c|c|c|c|c|c|c|c|c|}
\hline Tanggal & Intensitas tetesan & $\mathrm{pH}$ & DHL & Temp & Eh & TDS & $\mathrm{Ca}^{2+}$ & $\mathrm{Mg}^{2+}$ & $\mathrm{Na}^{+}$ & $\mathrm{Cl}^{-}$ & $\mathrm{HCO}_{3}^{-}$ & $\mathrm{SO}_{4}^{-}$ & $\log \mathrm{PCO}_{2}$ & SI calcite \\
\hline $05 / 23 / 200612.50$ & 198 & 7,22 & 436 & 25,3 & -14 & 284,9 & 2,87 & 0,18 & 0,09 & 0,77 & 3,06 & 0,07 & $-1,94$ & $-0,17$ \\
\hline $07 / 20 / 200611.00$ & 50 & 8,29 & 463 & 26,2 & -70 & 278,5 & 2,78 & 0,35 & 0,35 & 0,31 & 3,00 & 0,13 & $-3,03$ & 0,86 \\
\hline $08 / 23 / 200613.30$ & 12 & 8,33 & 361 & 26 & -74 & 184,2 & 1,97 & 0,35 & 0,32 & 0,15 & 1,82 & 0,13 & $-3,28$ & 0,56 \\
\hline $09 / 21 / 200613.45$ & 8,6 & 8,57 & 380 & 25,9 & -101 & 290,0 & 3,99 & 0,08 & 0,10 & 0,26 & 00 & 13 & -3 & \\
\hline $11 / 16 / 200613.00$ & 8 & 6,67 & 433 & 27,1 & 16 & 286,8 & 3,12 & 0,25 & 0,10 & 0,21 & 3,29 & 0,09 & $-1,37$ & -0, \\
\hline $12 / 21 / 200613.00$ & 5,6 & 7,1 & 438 & 26,1 & -7 & 175,0 & 0,60 & 1,47 & 0,13 & 0,22 & 2,05 & 0,09 & $-2,00$ & $-1,10$ \\
\hline $03 / 22 / 200713.00$ & 540 & 7,14 & 436 & 26,3 & -28 & 324,3 & 3,25 & 0,26 & 0,07 & 0,09 & 4,06 & 0,02 & $-1,75$ & $-0,07$ \\
\hline
\end{tabular}


Gilap yang menunjukkan banyak terdapatnya rongga-rongga (lapies) pada singkapan batuan.

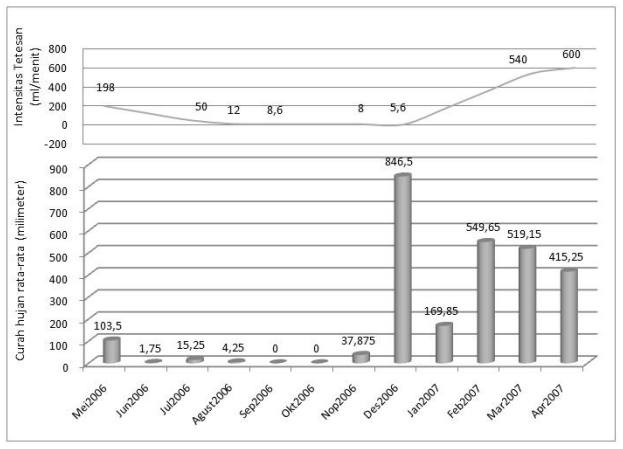

Gambar 1 Grafik intensitas tetesan (atas) dan curah hujan (bawah) selama satu tahun

Selanjutnya, dari Gambar 1.2, terlihat bahwa intensitas tetesan pada Gua Gilap mempunyai hubungan dan berkorelasi positif dengan TDS, DHL, Eh, kandungan ion $\mathrm{HCO}_{3}{ }^{-}$, dan $\mathrm{Ca}^{2+}$, tekanan parsial gas $\mathrm{CO}_{2}$; serta berkorelasi negatif dengan $\mathrm{pH}$ dan SI kalsit. Pada saat musim penghujan, intensitas tetesan pada Gua Gilap cenderung tinggi, nilai TDS, DHL, Eh, kandungan $\mathrm{Ca}^{2+}$, kandungan $\mathrm{HCO}_{3}{ }^{-}$, dan $\mathrm{PCO}_{2}$ terukur juga tinggi; sedangkan pH cenderung asam dan SI kalsit cenderung undersaturated. Sebaliknya, pada saat musim kemarau, intensitas tetesan pada Gua Gilap relatif rendah, nilai TDS, DHL, Eh, kandungan $\mathrm{Ca}^{2+}$, kandungan $\mathrm{HCO}_{3}^{-}$, dan $\mathrm{pCO}_{2}$ terukur juga rendah; sedangkan $\mathrm{pH}$ cenderung basa dan SI kalsit cenderung supersaturated.
Hal tersebut menunjukkan bahwa kondisi musim menyebabkan terjadinya variasi intensitas tetesan, dimana pada saat musim hujan, intensitas tetesan pada ornamen drapery di dalam Gua Gilap menjadi meningkat, dan sebaliknya, pada saat musim kemarau intensitas tetesan berkurang. Variasi intensitas tetesan tersebut kemudian berpengaruh pula terhadap kondisi hidrogeokimia tetesan yang terjadi. Selain itu, kondisi agresivitas tetesan juga terpengaruh oleh kondisi curah hujan dan besarnya intensitas tetesan. Pada saat musim hujan, dimana intensitas tetesan meningkat, kondisi air tetesan dari ornamen drapery pada Gua Gilap tersebut menunjukkan agresivitas yang tinggi atau masih mampu untuk melarutkan mineral kalsit. Sementara itu, pada saat musim kemarau, kondisi air tetesan cenderung jenuh terhadap mineral kalsit atau agresivitasnya berkurang.

Faktor lain yang mempengaruhi kondisi agresivitas tetesan adalah waktu kontak airtanah terhadap mineral kalsit dan jenis akuifer yang berperan. Pada saat musim penghujan, pada ornamen drapery yang dominan dipengaruhi oleh akuifer fissure, waktu kontak airtanah 


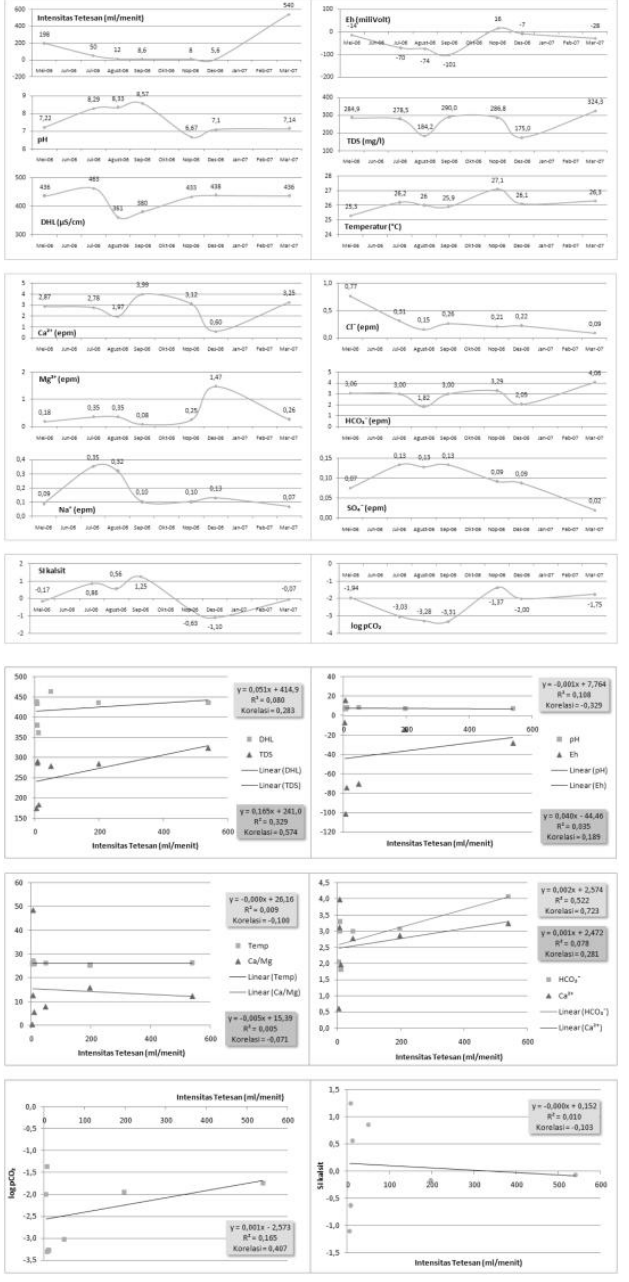

Gambar 1.2 Grafik Hidrogeokimia Tetesan dan Analisis Korelasi antara Intensitas dengan Hidrogeokimia Tetesan

terhadap batuan yang dilaluinya relatif singkat karena alirannya mengalir melalui celah dan retakan. Sebaliknya, pada saat musim kemarau, waktu kontak airtanah terhadap batuan yang dilaluinya relatif lama sehingga airtanah menjadi jenuh terhadap mineral kalsit dan mengurangi tingkat agresivitas airtanah tersebut terhadap mineral kalsit.
Selain itu, kandungan gas $\mathrm{CO}_{2}$ juga menjadi penyebab terjadinya variasi agresivitas airtanah terhadap mineral kalsit. Semakin tinggi tekanan parsial gas $\mathrm{CO}_{2}$ di atmosfer, maka semakin besar agresivitas airtanah terhadap mineral kalsit, dan begitu juga sebaliknya.

\section{Kesimpulan}

Kesimpulan yang diperoleh dari penjelasan di atas adalah kondisi musim mempengaruhi kondisi intensitas, hidrogeokimia, dan agresivitas tetesan yang terjadi pada ornamen drapery di dalam Gua Gilap. Selain itu, kondisi hidrogeokimia tetesan dipengaruhi pula oleh faktor jenis akuifer dan tekanan parsial gas $\mathrm{CO}_{2}$ yang terdapat di atmosfer. Di dalam penelitian mengenai hidrogeokimia airtanah pada daerah karst, perlu diperhatikan mengenai besarnya curah hujan, kondisi batuan atau jenis akuifer yang berperan, dan kondisi tekanan parsial gas $\mathrm{CO}_{2}$ yang terdapat di atmosfer maupun yang terdapat di dalam tanah, atau dengan kata lain, perlu diperhatikan interaksi antara air, batuan, dan gas.

\section{Daftar Pustaka}

Hariadi, B. 2008. Studi Variasi Temporal Kandungan Geokimia Air Tetesan Gua di Kawasan Karst Gunungsewu, Kabupaten Gunungkidul, Daerah Istimewa Yogyakarta: Kasus pada 
Ornamen Drapery di dalam Gua Gilap dan Ornamen Stalaktit di dalam Gua. Skripsi Sarjana, Fakultas Geografi UGM, tidak diterbitkan

Haryono, E., \& Adji, T. N. 2004. Pengantar Geomorfologi dan Hidrologi Karst. Fakultas Geografi Universitas Gadjah Mada, Yogyakarta

Liu, Z.; Yuan, D.; Maiman, J.; Jiang, G.; and He, S. 2003. Wet Season Hydrochemistry of the Southwest China Peak Cluster Karst. University of Memphis Conference Center: Fogelman Executive Center 308, USA

Suhartono, S. G., Subanar. 2005. A Comparative Study of Forecasting Models for Trend and Seasonal Time Series: Does Complex Model Always Yield Better Forecast Than Simple Models?. Jurnal Teknik Industri, Vol. 7, No. 1, Juni 2005:22-30

White, W. B. 1988. Geomorphology and Hydrology of Karst Terrains. Oxford University Press, New York 